\title{
Jornal das Senhoras - a interatividade no primeiro jornal feminino editado no Brasil $^{1}$
}

\begin{abstract}
Marco Aurelio REIS ${ }^{2}$
Cláudia de Albuquerque THOMÉ ${ }^{3}$

Resumo:

Os debates em torno da interatividade contemporânea dos leitores com os meios de comunicação fomentam a análise do presente artigo, que buscou no pioneiro semanário feminino Jornal das Senhoras (1852-1855) elementos de filiação dessa prática com os primórdios da imprensa no Brasil. Com a consulta facilitada pela digitalização das edições do periódico histórico pela Biblioteca Nacional, foi possível pinçar dados concretos da cultura participativa e de interatividade no jornal e analisá-los a partir da metodologia proposta por Luiz Gonzaga Motta (2013). Com isso, foi possível perceber a cultura participativa e a interatividade na chamada primeira fase do jornalismo brasileiro, bem como destacar as estratégias adotadas pelas pioneiras redatoras do Jornal das Senhoras para manter o semanário feminino vanguardista por quase quatro anos: jornalismo cidadão certificado pelas redatoras, jornalismo colaborativo com espaço cativo, linguagem direta e clara ao se dirigir ao público-alvo bem definido e linha editorial defendida nas páginas por redatoras e assinantes-colaboradoras.
\end{abstract}

Palavras-chave:

Narrativa jornalística. Cultura participativa. Interatividade. Jornal das Senhoras

\section{Jornal das Senhoras - interactivity in first female newspaper published in Brazil}

\begin{abstract}
:
Discussions on contemporary interactivity of readers with the media promote the analysis of this article, which sought the female pioneer weekly Jornal das Senhoras (1852-1855) affiliation elements of this practice with the beginning of the press in Brazil. With the access facilitated by digitization of historical editions of the journal by the Biblioteca Nacional, it was possible pinch concrete data of participatory culture and interactivity in the paper and analyze them from the methodology proposed by Luiz Gonzaga Motta (2013). So, it was possible to see the participatory culture and interactivity in the so-called first phase of Brazilian journalism, as well as highlighting the strategies adopted by the pioneering writers the Jornal das Senhoras to keep the avant-garde female weekly for almost four years: citizen journalism certified by writers, collaborative journalism, direct language to the public and editorial defended pages for writers and subscriber-collaborators.

Keywords:

Journalistic narrative. Participatory culture. Interactivity. Jornal das Senhoras

\section{Jornal das Senhoras - interactividad en primer periódico femenino publicado en Brasil}

Resumen:

\footnotetext{
${ }^{1}$ Artigo consolidado a partir das modificações feitas no trabalho apresentado no GT - História da Mídia Impressa - Alcar Sudeste, 2016.

2 Jornalista, mestre e doutor em Ciência da Literatura, professor do curso de Jornalismo e bolsista de Pesquisa e Produtividade na UNESA/RJ. Líder do grupo de pesquisa/CNPq Narrativas midiáticas e dialogias.E-mail: mreis1968@gmail.com.

3 Jornalista, mestre em Comunicação e Cultura e doutora em Ciência da Literatura, professora da Facom/UFJF e do PPGCOM/UFJF. Líder do grupo de pesquisa/CNPq Narrativas midiáticas e dialogias. E-mail: cthomereis@gmail.com.
} 
Los debates en torno a la interactividad contemporánea de los lectores con los medios de comunicación fomentan el presente estudio, que buscó en el pionero semanario femenino Jornal das Senhoras (18521855) elementos de filiación de esa práctica en los primordios de la prensa en Brasil. Con la consulta facilitada por la digitalización de las ediciones del periódico por la Biblioteca Nacional, fue posible destacar datos concretos de la cultura participativa y de interactividad en el periódico y analizarlos a partir de la metodología propuesta por Luiz Gonzaga Motta (2013). Con eso, fue posible percibir la cultura participativa y la interactividad en la llamada primera fase del periodismo brasileño, así como destacar las estrategias adoptadas por las pioneras redactoras del Jornal das Senhoras para mantener el semanario femenino vanguardista por casi cuatro años: periodismo ciudadano certificado por las redactoras , periodismo colaborativo con espacio cautivo, lenguaje directo y claro al dirigirse al público bien definido y línea editorial defendida en las páginas por redactores y suscriptores-colaboradoras.

Palabras clave:

Narrativa periodística. Cultura participativa. Interactividad. Jornal das Senhoras

\section{Introdução}

A interatividade entre veículos de comunicação e seus leitores, ouvintes ou telespectadores foi acelerada após a chamada internet $2.0^{4}$, quando o avanço tecnológico facilitou a participação do público no conteúdo produzido. Em função dessa aceleração, a interatividade no jornalismo tem levado a acalorados debates sobre o modelo ideal de negócio para o jornalismo digital (COSTA, 2014) e sobre as transformações de toda a mídia em um cenário marcado pela cultura participativa ${ }^{5}$ (JENKINS, 2009), entre outras reflexões.

Em meio a esses debates, despontam discussões sobre como deve ser o gerenciamento dessa interatividade pelos meios de comunicação. O presente artigo resulta de reflexões sobre a interatividade nos meios de comunicação durante a pesquisa "O modelo de negócio do jornalismo tradicional reage no Rio de Janeiro", com o objetivo de estudar como a cadeia tradicional do jornalismo vem reagindo aos desafios impostos pelo avanço tecnológico. Levantamento feito em 2015 e 2016 em pesquisa de campo $^{6}$, nas redações dos principais jornais do Rio de Janeiro, destaca que os diretores e os editores estimulam a interatividade dos veículos com leitores por meio do WhatsApp, de endereços de $e$-mails de repórteres publicados nas aberturas de reportagens impressas e por seus sites, mas não montam estruturas específicas para uma efetiva relação interativa. Ou seja, em função do volume recebido, nem todos os leitores, ouvintes ou telespectadores têm suas colaborações veiculadas ou seus questionamentos respondidos.

\footnotetext{
4 Termo cunhado em 2004 pela empresa norte americana O'Reilly Media, para nomear a revolução decorrente da popularização dos blogs e dos chats, das mídias sociais colaborativas, das redes sociais digitais, que alargaram as possibilidades de interatividade entre produtores e consumidores de conteúdo informativo.

5 Nos termos de Henry Jenkins (2009, p. 325), trata-se da forma como o público encara a conexão, incluindo a internet, "como um veículo para ações coletivas".

${ }^{6}$ Levantamento feito na pesquisa "O modelo de negócio do jornalismo tradicional reage no Rio de Janeiro", com apoio da UNESA/RJ, instituição de ensino a que um dos autores está vinculado.
} 
Tal ação evidentemente frustra colaboradores e tem potencial de inibir futuras colaborações e intervenções, em um processo que pode ser visto como um dos ingredientes da crise de audiência de emissoras de rádio e TV e queda de vendas em banca e assinaturas de jornais impressos (REIS, 2015).

A proposta do presente trabalho é colaborar com essas discussões, voltando no tempo para detectar que tais fenômenos de participação do público na imprensa não são tão novos assim e não dependem de questões meramente tecnológicas, mas sim de contextos sociais e culturais. Nesta perspectiva, pretende-se aqui resgatar como a cultura participativa e a interatividade inerente a ela foram tratadas como peças fundamentais do primeiro jornal feminino impresso no Brasil, o Jornal das Senhoras ${ }^{7}$, editado entre 1852 e 1855. O periódico semanal do início do Segundo Reinado, comandado por mulheres, tem seu pioneirismo destacado em trabalhos de História e de Comunicação (LIMA, 2012), sobretudo em relação às suas ideias sobre emancipação feminina em um momento em que a educação, o trabalho qualificado e o status social eram privilégio quase que estritamente masculino em solo brasileiro.

Com base na metodologia proposta por Motta (2013), em sua obra referencial Análise Crítica da Narrativa ${ }^{8}$, o presente trabalho buscou destacar, nos artigos jornalísticos publicados pelo Jornal das Senhoras, elementos textuais que evidenciam o cuidado com o qual as pioneiras jornalistas administravam a interatividade com suas "assinantes", em um cenário em que a comunicação entre jornal e leitores somente podia se dar por carta, elemento de comunicação interpessoal que, no Brasil, passara a ser entregue nas residências em 1835 (CORREIOS, s.d.), ou seja, apenas 17 anos antes da primeira edição do semanário em estudo. As edições analisadas integram o acervo composto de 156 exemplares digitalizados pela Biblioteca Nacional, disponibilizados

\footnotetext{
${ }^{7}$ Até a edição ${ }^{\circ}$ 09, de 27 de fevereiro de 1853, o nome do periódico era O Jornal das Senhoras. Na edição ${ }^{\circ} 10$, de 06 de março, o título passou a ser Jornal das Senhoras. Neste trabalho utilizaremos o nome sem o artigo.

${ }^{8}$ Com base em termos e recursos oriundos de outras teorias de análise narrativa, Motta (2013) cria seu próprio modus operandi. $\mathrm{O}$ autor considera que o analista deve realizar movimentos para a análise: compreender a intriga como síntese do heterogêneo; aprender a lógica do paradigma narrativo a partir de uma leitura do conjunto dos textos; deixar surgirem novos episódios; permitir ao conflito dramático se revelar e permitir aflorar as metanarrativas em um olhar qualitativo. Foi neste último movimento que a pesquisa que originou este artigo se baseou para a análise do Jornal das Senhoras: a partir de uma leitura inicial, identificamos elementos que se repetem e destacamos unidades exemplares para a chamada análise qualitativa.
} 
para download pela instituição em sua plataforma digital desde $2012^{9}$, sobre os quais foram feitas leituras flutuantes para seleção das edições avaliadas de forma qualitativa.

Diante da amostragem disponível e do fato de algumas poucas edições digitalizadas apresentarem erro no download, como a do dia 26 de setembro de 1852 , optamos pela avaliação qualitativa, que destacou material para análise nos moldes propostos por Motta (2013). A leitura flutuante se deu nas edições disponíveis, no universo de 156 exemplares, buscando na plataforma digital palavras-chave que indicavam estímulo à interatividade, tais como "cartas", "assignantes" e "amigas". Após a busca, foram selecionados momentos exemplares e de maior destaque editorial que mostram a interação das jornalistas com suas leitoras, sendo eles mais frequentes em 1852, primeiro ano da publicação. A partir desse conjunto de trechos, que forma o que Motta (2013, p. 137-138) conceitua como "plano da estória", a pesquisa partiu para a análise qualitativa, no intuito de chamar a atenção para a interatividade nos primórdios da imprensa brasileira.

\section{"Uma senhora à testa da redação de um jornal"}

Publicado pela primeira vez em $1^{\circ}$ de janeiro de 1852, uma quinta-feira, o Jornal das Senhoras estreia quando o imperador D. Pedro II tinha 26 anos de idade e um mês depois do fim da chamada Revolução Praieira, o movimento pernambucano de caráter liberal e federalista que balançara o segundo reinado, instaurado 21 anos antes. O semanário circularia no Rio de Janeiro, sede da corte imperial, e logo em sua primeira edição se dirigiria diretamente às suas leitoras, chamadas de "As nossas Assignantes", deixando clara sua linha editorial em prol da emancipação feminina: "Ora, pois, uma senhora à testa da redação de um jornal! Que bicho de sete cabeças será?” (JORNAL DAS SENHORAS, $1^{\circ}$ jan. 1852 , p. 1).

No mesmo artigo, a colaboração das leitoras será estimulada, indicando literalmente que a identidade das colaboradoras será mantida no anonimato.

Confidente discreto das vossas producções literárias; ellas serão publicadas debaixo do anônimo: porem não temaes confiar-mo-las, nem temaes dar expanção ao vosso pensamento; se o possuis é porque é dom da Divindade, e

\footnotetext{
${ }^{9}$ Disponível em:

<http://objdigital.bn.br/acervo_digital/div_periodicos/per700096/per700096 anuario.htm>, acesso no período de 10/01/2016 a 20/02/2016.
} 
aquillo que Deus dá, os homens não podem roubar. (JORNAL DAS SENHORAS, $1^{\circ}$ jan. 1852, p. 1$) .^{10}$

$\mathrm{Na}$ mesma edição, seriam divulgados, na oitava e última página, os endereços para envio das cartas. Uma ação que se repetiria nas edições seguintes.

\begin{abstract}
Subscreve-se para este Jornal nas cazas dos Snrs Wallerstein e C. n. 70, a. e F. Desmarais n. 86, Mongie n. 87, rua do Ouvidor; e na Typografia Parisiense, rua Nova do Ouvidor, n. 20. Toda a correspondência é dirigida em carta fechada á Redactora em chefe a qualquer das cazas mencionadas. (JORNAL DAS SENHORAS, $1^{\circ}$ jan. 1852 , p. 8).
\end{abstract}

A interatividade solicitada logo seria aceita pelas assinantes, que pagavam 3 mil-réis, se morassem na Corte, ou 4 mil-réis, se residissem nas províncias, para receber as edições semanais do Jornal das Senhoras por três meses. Na edição de número 6, publicada em 8 de fevereiro de 1852, uma colaboração por carta mantida no prometido anonimato ganha espaço nas páginas:

\begin{abstract}
A vossa nobre coragem, senhora, tem me de tal modo impressionado, que não posso deixar de felicitar-vos pela alta consideração que mereceis. Não é porque fosseis a primeira senhora que emprehendeu a diffícil tarefa do jornalismo, nem pelo útil entretenimento que dais as do nosso sexo sobre modas: não; é pelos sublimes e tocantes pensamentos com que desenvolveis as nossas intelligencias no perfeito conhecimento do que nos cumpre saber para desempenho de nossa missão como filhas, esposas e mães. (JORNAL DAS SENHORAS, 8 fev. 1852, p. 44).
\end{abstract}

$\mathrm{Na}$ mesma edição, mais espaço para outra correspondência, com elogios à iniciativa. Nessa, porém, um questionamento evidencia a predisposição para o diálogo, mesmo lançando mão de uma pergunta retórica, que teria como resposta o jornalismo colaborativo, com a assinante tendo seu questionamento publicado:

Nem eu sei como agradecer-lhe este benefício que nos faz á todas, pois que estou certa que todas como eu são unânimes em tributar-lhe votos de gratidão pela empreza que tomou á hombros. (...) A senhora veio-nos abrir um campo de actividade, em que podemos exercitar as nossas forças, e sahir do nosso estado de vegetação. Como lhe agradeceremos? (JORNAL DAS SENHORAS, 8 fev. 1852, p. 44).

O pesquisador Nelson Werneck Sodré descreve o ambiente onde nasceu o Jornal das Senhoras, definido por ele como sinal das diferenciações progressivas pelas quais passava a sociedade brasileira no início do segundo reinado (SODRÉ, N.W., 1977, p.

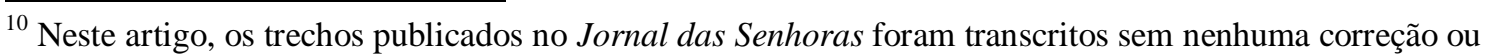
atualização do idioma, levando em consideração que o texto original carrega informação sobre aquele momento histórico da imprensa brasileira.
} 
214). O autor frisa que o império entrava na segunda metade do século XIX com uma estrutura articulada e firme, mesmo frente aos apelos de mudança que ganhariam força após a Guerra com o Paraguai (1864-1870). É marcante, destaca Nelson Werneck Sodré, o fim do tráfico negreiro legalizado (1850), a ascensão da importância econômica da lavoura de café e a disponibilidade de capital, antes empregado no comércio internacional de escravos. Investe-se, então, em ferrovias (para o escoamento do café) e na navegação a vapor. Desenvolve-se o comércio, o sistema bancário e até a indústria, dando espaço para o surgimento de figuras proeminentes na economia nacional, como o Barão de Mauá, e de jornais como o das Senhoras.

Nelson Werneck Sodré (1977, p. 114) afirma que o jornal feminino pioneiro teria sido lançado pela baiana Violante Ataliba Ximenes de Bivar e Velasco, mas, posteriormente, historiadores, como a professora Joelma Varão Lima, e pesquisadores da literatura feminina hispânica, como a professora Karine da Rocha Oliveira, detectaram que o Jornal das Senhoras fora fundado pela feminista argentina Joana Paula Manso de Noronha.

\footnotetext{
Joana Paula Manso de Noronha atuou como redatora do periódico durante seis meses. A jornalista, de nacionalidade argentina, havia se separado do marido (um compositor e violonista português) e morava na Corte, onde lecionou, atuou em vários jornais e publicou diversos trabalhos literários. Joana Paula, primeira redatora do jornal em comento, foi substituída por Violante Ataliba Ximenes de Bivar e Velasco. (LIMA, 2010, p. 228).
}

O jornal contava com seções de Moda (com figurinos franceses especialmente importados), Belas Artes, Teatro e Crítica, além de publicar partituras de piano e folhetins. O periódico passaria a ser comandado por Violante na edição de número 27 , de 4 de julho de 1852, ou após 215 páginas impressas. No texto de despedida que faz para sua antecessora, a nova redatora-chefe reforça o apelo pela manutenção da interatividade:

\footnotetext{
Apresentando-me á vos, eu ouso pedir-vos que continueis a favorecer, como eis deito, o Jornal das Senhoras (grifo da publicação), para que ele atinja ao gráo de perfeição de que é merecedor. [...] Acceitae, minhas amigas, os meus protestos de pura affeição por vós, a quem mil bens apeteço. (JORNAL DAS SENHORAS, 4 jul.1852, p. 27).
}

Como destaca Marialva Barbosa (2013, p. 73-96), as dificuldades encontradas por jornais daquela época eram imensas, a começar pelo público leitor, uma vez que a maioria da população era analfabeta. Tal quadro se agravava quando o público-alvo era formado por mulheres. Com as máquinas impressoras sendo importadas e com 
manuseio dependente da contratação da escassa mão de obra qualificada, o custo para rodar uma publicação era imenso, o que explica os apelos frequentes feitos pelas redatoras do jornal pioneiro para renovação de assinaturas, como o feito na edição de número 13, de 27 de março. (JORNAL DAS SENHORAS, 27 mar. 1852, p. 103).

\begin{abstract}
Tais dificuldades levaram o jornal a encerrar suas atividades no dia 30 de dezembro de 1855, com o semanário, então, sob o comando de Gervásia Neves, sua terceira redatora chefe. Em todo seu período de existência foram impressas 416 páginas. Depois de um ano de circulação do jornal (1853), Violante deixou a editoria, passando o cargo a Gervásia Neves. Uma mesma razão levou as duas primeiras jornalistas a deixarem a redação do jornal: a falta de recursos financeiros para manter a publicação de um periódico semanal que sobrevivia graças às assinaturas e aos recursos próprios das suas diretoras. Gervásia Neves, casada com o senhor Antônio José dos Santos Neves, foi apoiada financeiramente pelo marido. Entretanto, no número de 30 de dezembro de 1855 , a redatora avisou às leitoras que, por motivos particulares, o "Jornal das Senhoras" não circularia em 1856, mas poderia voltar em 1857, o que, todavia, não aconteceu. (LIMA, 2010, p. 228).
\end{abstract}

Das três redatoras, tem-se notícia que apenas Violante continuou à frente de um jornal de sonetos, cartas de amor e modas, publicado na cidade do Rio de Janeiro e intitulado $O$ Domingo, cuja existência se prolongou até o ano de 1875, quando a jornalista faleceu (SODRÉ, N. W., 1977, p. 214). Joana Paula Manso de Noronha, mesmo longe das páginas, se manteria na militância pela igualdade entre homens e mulheres até sua morte, em 1875 (LOBO, 2009). Sobre o destino de Gervásia, sabe-se apenas que sob seu comando os artigos abordando de forma explícita a emancipação feminina ficaram raros no Jornal das Senhoras, sendo o tema tratado de forma mais sutil a partir das edições de 1853, mas mantida, porém, a proposta inicial de estímulo à interatividade com as leitoras colaboradoras.

\title{
Lições de interatividade no jornalismo feminino pioneiro
}

O conceito cultura participativa nas mídias se firmou ante a comparação dos meios de comunicação contemporâneos com seus antecessores, em que a passividade dos espectadores era uma premissa. No ambiente da cultura participativa, afirma Jenkins (2009, p. 28), “em vez de falar sobre produtores e consumidores de mídia como ocupantes de papéis separados", pode-se "agora considerá-los como participantes interagindo de acordo com um novo conjunto de regras, que funcionam no ambiente da cultura da convergência permitida por aparelhos de comunicação digital" facilitadores da chamada interatividade. 
Ao falar da disrupção da chamada cadeia tradicional de jornalismo no estudo em que propõe um novo modelo de negócio para o jornalismo digital, Caio Túlio Costa (2014, p. 12) destaca, como faz o professor Muniz Sodré (2002, p. 16), o momento atual em que, entre outros elementos ligados às novas formas de distribuição de conteúdo, uma das marcas é o jornalismo cidadão, no qual pessoas sem formação jornalística participam de forma ativa no processo de reportagem, servindo o meio de comunicação como certificador ${ }^{11}$ do conteúdo aglutinado em suas páginas, em minutos de gravações de áudio ou em tempo de TV. A discussão é sobre o futuro dos jornais tradicionais no presente momento em que ações como o jornalismo cidadão concorrem com a cadeira tradicional. Porém, levando o mesmo olhar para o jornalismo feito pelas assinantes e redatoras do Jornal das Senhoras, é possível identificar no processo de cidadania feminina ${ }^{12}$ um elemento que tornava viáveis operacional e financeiramente as edições exatamente por ser o semanário um certificador dos textos de suas assinantescolaboradoras. As próprias redatoras usavam recursos familiares para garantir as edições dos jornais e, como foi apontado acima, duas deixaram a função em decorrência de dificuldades econômicas.

Cabe, portanto, ver como esse jornalismo cidadão ${ }^{13}$ do Jornal das Senhoras, envolvido em uma cultura participativa embalada por feedbacks por carta, cuidava para manter ativa a interatividade ${ }^{14}$ com suas assinantes, que viam a publicação como certificadora de seus pensamentos vanguardistas sobre a emancipação feminina. Para tanto, seguindo os movimentos de análise crítica da narrativa propostos por Motta (2013, p. 119-209), já citados, são destacáveis, nas edições do semanário preservadas pela Biblioteca Nacional, elementos que podem mostrar como se dava o processo de estímulo e manutenção da interatividade das assinantes com o jornal feminino do

\footnotetext{
${ }^{11}$ De acordo com Marcelo Rech, presidente do Fórum Mundial de Editores, que representa cerca de 20 mil executivos e chefes de redação, em entrevista para o jornal Zero Hora publicada em 31 de maio de 2015, "o Jornalismo profissional tem de ser ainda mais profundo, mais preciso, mais independente, mais transparente, para se diferenciar dos oceanos informativos disseminados pelas redes sociais sem selo de origem. O papel do jornalista e dos veículos será cada vez mais o de certificador da realidade, numa espécie de avalista de que fatos e comentários que já circulam por aí são verdadeiros ou não, e em que medida" (CLICRBS, 2015)

${ }^{12}$ Fala-se aqui em cidadania uma vez que os textos pela emancipação feminina eram escritos pelas assinantes, convocadas pelas redatoras-chefes a renovar suas assinaturas para manter o jornal ativo.
}

${ }^{13}$ O presente artigo baseia-se na conceituação de FOSCHINI e TADDEI (2006, p. 14) sobre Jornalismo Cidadão, no qual predomina o olhar sobre o qual o "jornalismo cidadão é uma conversa entre quem faz a notícia e quem a recebe".

\footnotetext{
${ }^{14}$ Seguindo os termos propostos por LÉVY (1993), em que, no contexto da cibercultura, interatividade passou a ser uma das características dos meios de comunicação após a popularização da Internet.
} 
Segundo Reinado, buscando elementos que podem colaborar com o momento contemporâneo do jornalismo.

O primeiro elemento que salta aos olhos é ligado ao plano da expressão, à linguagem usada pelas redatoras do Jornal das Senhoras ao se dirigirem às suas assinantes. Logo a partir da primeira edição, fica evidente a disposição para se travar um diálogo. Ao questionarem: “Ora, pois, uma senhora à testa da redação de um jornal! Que bicho de sete cabeças será?" (JORNAL DAS SENHORAS, 1952, p. 1), no editorial de inauguração do jornal, em $1^{\circ}$ de janeiro, as redatoras evidenciam um estilo que se repetiria na maioria das edições analisadas, algumas vezes simulando diálogos:

\footnotetext{
Não posso deixar de confessar-vos que estou alegríssima, satisfeitíssima, e ainda mais, pulando de contente! Talvez penseis, pela declaração, que tirei a sorte grande na loteria passada? Oh! Não o podeis crer: o dinheiro não é nossa verdadeira felicidade; vós bem sabeis. (JORNAL DAS SENHORAS, 17 out. 1852 , p. 124).
}

Cabe notar o uso, no "diálogo" simulado, da hipérbole, figura de linguagem que o jornalismo lança mão para enfatizar fatos objetivando um efeito surpresa no leitor (MOTTA, 2013, p. 136). Ou seja, trata-se de outra estratégia retórica para dialogar com as leitoras. $\mathrm{O}$ mesmo pode-se dizer do uso corriqueiro nas edições de verbos conjugados na primeira pessoa do plural, como em "Leiamos, querida leitora, o que diz D'Alembert" (JORNAL DAS SENHORAS, 15 ago. 1852, p. 51), para envolver as assinantes, tratadas no singular "leitora", numa invocação do ato individual de leitura.

Um segundo elemento diz respeito ao plano das histórias contadas, com conteúdos envolventes, sendo que a colaboração direta das leitoras aparece em uma a cada duas edições, o que foi detectado pela leitura flutuante feita por esta pesquisa. Nesse plano, a apresentação dos textos pelas redatoras e o texto escrito pelas assinantescolaboradoras e transcrito pelas redatoras interagem com a assinante-leitora, também envolvida por elementos do plano da linguagem, mas, sobretudo, fisgada no plano do enredo do que é narrado. Caso exemplar é uma carta escrita por uma leitora que afirma, no texto, ter somente "quatorze primaveras e meio outono". A autora, identificada como Maria Clementina da Cruz, é qualificada pela redatora como "intelligente" colaboradora, de Pernambuco. A colaboração chegara à redação, informa o texto de apresentação, por intermédio do irmão da colaboradora, este, integrante da Corte real. O conteúdo, porém, é o principal elemento da interatividade da assinante-colaboradora com o jornal, em função de sua afinidade com a linha editorial até então apresentada. A 
jovem questiona a educação dada às moças, limitada e restrita.

\begin{abstract}
Quando a maior parte dos pais de família procurarão dar educação ás suas filhas, franca, completa e liberal? Quando nã.[sic] se desapreciarão as suas faculdades intellectuaes e quando finalmente tentar-se-há cultivar a sua intelligência, deixando que a liberdade do pensamento fluctue em seus escriptos? Não entendo que uma mulher por saber musica, tocar piano, coser, bordar, marcar e escrever, tenha completada a sua educação. (JORNAL DAS SENHORAS, 29 ago. 1852, p. 67).
\end{abstract}

No mesmo texto enviado pela jovem assinante de Pernambuco é possível identificar a militância feminina em tom firme, opinativo e direto em uma sociedade dominada por homens. Tal elemento deixa evidente a escolha editorial das redatoras de valorizar o olhar vanguardista da assinante-colaboradora, certificado por elas ao publicarem o texto na íntegra, mesmo tendo palavras e frases fortes e pouco usuais à época.

Pelo que já foi dito, podemos concluir que as mulheres pensão e raciocinão como os homens, e às vezes com mais acerto. Ora, agora devemos acrescentar que sua fraqueza primitiva concorre para dar facilidade ao livre exercício dos deveres que a razão julgou acertado prescrever, por que, supondo o caracter da sensibilidade desenvolvido, todas as faculdades da mulher se lanção para o lado do bem voluntariamente. (JORNAL DAS SENHORAS, 29 ago. 1852, p. 68).

Também na esfera do conteúdo, nota-se a valorização do jornalismo cidadão, evidenciado na forma como as redatoras destacam a importância das assinantes para manutenção do semanário, uma marca que pode ser vista também no editorial de abertura da última edição do Jornal das Senhoras.

Há quatro anos é o JORNAL DAS SENHORAS [grifo das redatoras] protegido por um crescido número de assinantes que constantemente tem sustentado com as avultadas despesas de uma publicação de sua ordem. Ainda não havia esmorecido, nem uma só, sua tão franca e leal proteção. Nem tão pouco nós esmoreceremos, Senhoras. Não esmoreceremos jamais. Fazemos apenas uma parada, que julgamos necessária, no próximo anno de 1856; e com favor de Deus o JORNAL DAS SENHORAS reapparecerá em 1857, para prosseguirmos ao honroso fim a que nos proposemos, cultivando com esmero as immarcesciveis flores do caminho tão nobremente encetado pela nossa antiga redactora, a Sra D. Joanna Paulo Noronha. (JORNAL DAS SENHORAS, 30 dez. 1855, p. 52).

Cabe destacar, na citação acima, ainda no plano do conteúdo, o uso do flashback, ao citar nominalmente a primeira redatora chefe, como uma maneira de contar o que une assinantes-leitoras, sejam elas pioneiras, não tão antigas, e novas, com a história do jornal, valorizando a cultura participativa, da qual a interatividade é elemento chave, e 
que foi uma constante ao longo do período de existência do semanário (de 1852 a 1855). Tal cultura participativa fica clara mesmo quando o jornal cobrava das assinantes uma resposta se desejavam ou não continuar a receber o semanário em suas casas:

Tendo finalizado o primeiro semestre de janeiro a junho, ainda persistimos no proposito de não suspender a entrega do JORNAL DAS SENHORAS a nenhuma de nossas Assignantes. As senhoras, que não quiserem continuar a hornar-nos com a sua assinatura, rogamos que tenhão a bondade de mandar sua participação à casa unicamente dos Srs Wallerstein \& C, rua do Ouvidor n. 70 (...). (JORNAL DAS SENHORAS, 17 jul. 1853, p. 232).

Já no tocante ao plano da metanarrativa ${ }^{15}$, são diversos os elementos que podem ser destacados como modelos exemplares de estímulo e manutenção da interatividade entre o Jornal das Senhoras e suas assinantes. O mais frequente deles diz respeito à forma carinhosa com que as assinantes eram tratadas pelas redatoras. $\mathrm{O}$ adjetivo "querida" é o mais frequente para qualificar as assinantes, mas outros no mesmo sentido ("amáveis", "amigas") indicam também a forma carinhosa como as redatoras se referiam às leitoras, sobretudo em textos de abertura e de encerramento, como pode ser conferido no texto de abertura da edição de 4 de julho de 1852, página 27 (“Acceitae, minhas amigas, os meus protestos de pura affeição por vós, a quem mil bens appeteço") e na última nota publicada na edição de 18 de julho de 1852, página 24(“Muito agradável é a notícia lyrica que temos que dar às nossas amáveis leitoras”).

$\mathrm{O}$ posicionamento das redatoras ao se dirigirem às suas colaboradoras é outro elemento a ser destacado dentro da proposta da metanarrativa. A posição em prol da emancipação feminina se evidencia, primeiramente, na escolha das colaborações a serem publicadas, como no caso do texto "Emancipação Moral da Mulher", endereçado à "Dignissíma Redactora em Chefe do Jornal das Senhoras" e publicado em 24 de outubro de 1852, dialogando com outro que fora veiculado na edição do domingo anterior. A força ideológica é evidente no texto de 24 de outubro:

\begin{abstract}
A escravidão das mulheres é uma herança funesta que o domínio dos Árabes deixou na península Ibérica, e que foi transmitido e implantado na America pelos conquistadores (...) Quando a mulher souber que de todos os gozos e os direitos que the outorga a mão poderosa do Omnipotente, ella foi despojada;quando houver uma lei que a proteja com sua força moral; quando essa lei disser ao pai desnaturado _ tu és pai e não tyrano; quando disser ao irmão usurpador, o único direito que tens sobre tua irmã é o de protecção (...) quando enfim a mulher deixar de ser cousa, então acalar-se-ha a guerra injusta". (JORNAL DAS SENHORAS, 24 out. 1852, p. 131).
\end{abstract}

\footnotetext{
15 A metodologia proposta por Motta (2013) prevê, em um dos seus movimentos, deixar aflorar as metanarrativas, considerando que toda narrativa se constrói com base em valores éticos e morais e têm, como pano de fundo, questões culturais e ideológicas.
} 
O mesmo tom ideológico partiria das mãos das redatoras em diversos textos, sendo notável a resposta dada pela redatora-chefe a uma carta assinada "O Homem", e tornada pública na edição de 8 de fevereiro de 1852 . No texto, intitulado "Resposta", a redatora explica que antes da publicação da segunda edição do Jornal das Senhoras recebera a tal carta, dirigida "privadamente" a ela e inicialmente mantida sem resposta em função das teorias expostas pelo autor, que não se identificava:

[...] julguei-me exonerada de responder, em primeiro logar porque não costumo conceder satisfações a pessoas que não conheço; em segundo logar porque, sendo as doutrinas do homem [escrito em itálico, grifo da redatora] muito repulsivas para mim, não sei porque motivo havia de procurar uma contenda, que tem todos os visos de uma tentativa de conversão. (JORNAL DAS SENHORAS, 08 fev. 1852, p. 41).

Tal carta, diz a redatora, ficaria sem resposta porque o autor revelara ser pertencente à escola "materialista, absolutista e inimiga do progresso do gênero humano". Por esse motivo, a redatora considerava não ter nada a dizer para o remetente. O autor anônimo enviaria, porém, uma segunda carta, que não ficou sem resposta:

Sois modesto por demais senhor, em supordes que a minha declaração sobre a emancipação da mulher, me fosse arrancada pela vossa carta; embora algum período dessa mesma declaração assim vo-lo fizesse supor; vossa carta em comparação à obra colossal a que me tenho proposto, é apenas mais um espinho na carreira perigosa que empreendi há dez anos. (JORNAL DAS SENHORAS, 08 fev. 1852, p. 41).

Adiante, o tom da redatora-chefe ficaria mais áspero com o autor da carta, aproximando o jornal de suas assinantes, por ser claramente simpático à emancipação feminina.

A mulher conhece quando é tyranisada, tem a consciência do que sente, não se revolta porque vive como cativo carregado dos ferros da oppressão (...) Agora que assás demonstrado que não sei recuar nas minhas ideias, que não tenho medo, e que sei argumentar, previno-vos que não responderei nem directa, nem indirectamente, às vossas cartas debaixo da assinatura do anônymo. (JORNAL DAS SENHORAS, 08 fev. 1852, p. 43).

Cabe, ainda recorrendo a movimento analítico sugerido por Motta (2013, p. 176195), ver como o semanário feminino transformava suas redatoras e assinantescolaboradoras em personas, buscando envolver quem as lia. Apresentadas como "queridas" (JORNAL DAS SENHORAS, 7 mar. 1853, p. 10) e também "boas e nobres" (JORNAL DAS SENHORAS, 30 dez. 1855, p. 52), redatoras e assinantes- 
colaboradoras são elementos de identificação com as demais assinantes. Os opositores da ideologia do semanário, como o anônimo da carta citada acima, são apresentados pelo jornal como vilões, tornando-se também elementos de identificação das assinantes com a publicação.

Esse processo de identificação pode ser visto como estímulo à cultura participativa e à interatividade inerentes ao Jornal das Senhoras, o que pode ser confirmado, por exemplo, na edição de 27 de março de 1852, página 103, quando uma colaboradora identificada como "Uma assignante" conta que, em Recife, uma jovem surda e muda toca piano "com perfeição". O caso é gancho para a autora se queixar que, diferentemente dos Estados Unidos e da Europa, no Brasil há poucas chances de estudo e formação para deficientes como a menina pernambucana. A resposta da redatora vem na forma do adjetivo "interessante", usado no título do comunicado, valorizando o tom de crítica ao Segundo Reinado no Brasil presente no texto enviado pela assinante colaboradora de Pernambuco, estado nordestino que anos antes abrigara, como dito anteriormente, a Revolução Praieira, movimento liberal que de 1848 a 1851 tentou sem êxito destituir do poder o imperador Pedro II.

\section{Considerações finais}

A cultura participativa e a interatividade tão presentes no atual momento por muitas vezes ofuscam olhar para ações similares, mesmo que limitadas pela tecnologia, ocorridas ao longo da história do jornalismo. Em tempos de acirrada competição entre os veículos de comunicação da cadeia tradicional do jornalismo, com a grande maioria sofrendo com menos receita publicitária e demissão de pessoal, as redes sociais e ações de jornalismo participativo são vistas ora como adversárias ora como única alternativa nesse cenário de crise acima descrito.

Perceber a cultura participativa e a interatividade na chamada primeira fase do jornalismo genuinamente brasileiro enriquece a discussão, sobretudo quando se destacam, como feito aqui, as estratégias adotadas pelas pioneiras redatoras do Jornal das Senhoras para manter o semanário feminino vanguardista por quase quatro anos: jornalismo cidadão certificado pelas redatoras, jornalismo colaborativo com espaço cativo e valorizado pela publicação, linguagem direta e clara ao se dirigir ao públicoalvo bem definido e linha editorial claramente defendida nas páginas por redatoras e assinantes-colaboradoras. 
O trabalho de resgate, favorecido pela digitalização de edições do raro periódico pela Biblioteca Nacional, chama a atenção para essas e outras estratégias de menor destaque usadas no Jornal das Senhoras. Cabe pontuar a lição que as históricas páginas podem dar aos dias de hoje, sobretudo, para jornalistas preocupados com o corte de vagas e a concentração de veículos nas mãos de grandes grupos de comunicação, cada vez mais hegemônicos em suas praças de circulação. $O$ conceito certificador no ambiente da cultura participativa e a interatividade inerente a ela são os elementos que mais chamam a atenção na presente análise.

\section{Referências}

BARBOSA, Marialva. História da Comunicação no Brasil. Petrópolis, RJ: Vozes, 2013.

CORREIOS. Sobre Correios: a empresa: história postal. Site, [s.d.]. Disponível em: <http://www.correios.com.br/sobre-os-correios/a-empresa/historia>. Acesso em: 24 maio 2016.

COSTA, Caio Tulio. Um modelo de negócio para o jornalismo digital. Revista de Jornalismo da ESPM, São Paulo, ano 3, nº 9, p. 54-115, abr, maio, jun. 2014.

CLICRBS. Diretor da RBS preside Fórum de Editores, Porto Alegre, 31 mai. 2015.

Disponível em: <http://anoticia.clicrbs.com.br/sc/noticia/2015/05/diretor-da-rbspreside-forum-de-editores-4772277.html>. Acesso em: 08 jun. 2018.

FOSCHINI, Ana Carmen; TADDEI, Roberto Romano. Conquiste a rede - jornalismo cidadão - você faz a notícia. Overmundo, ago. 2006. Disponível em: $<$ http://www.overmundo.com.br/banco/conquiste-a-rede-jornalismo-cidadao-voce-faza-noticia>. Acesso em: 14 out. 2016.

JENKINS, Henry. Cultura da convergência. 2. ed. São Paulo: Aleph, 2009.

JORNAL DAS SENHORAS: modas, literatura, belas-artes, teatros e crítica. Rio de Janeiro: Typ. Parisiense, 1852-1855. Disponível em: <http://objdigital.bn.br/acervo_digital/ div_periodicos/per700096/per700096_anuario.htm>. Acesso em: 10 jan. 2016.

LÉVY, Pierre. As tecnologias da inteligência: o futuro do pensamento na era da informática. São Paulo: Editora 34, 1993.

LIMA, Joelma Varão. O Jornal das Senhoras, um projeto pedagógico: mulher, educação, maternidade e corpo (Rio de Janeiro na segunda metade do século XIX). Projeto História, São Paulo, n. 45, p. 397-403, dez 2012. Disponível em: $<$ https://revistas.pucsp.br/index.php/revph/article/view/15023>. Acesso em: 25 jul. 
2015.

. "Jornal das senhoras": as mulheres e a urbanização na Corte. São Paulo,

Cadernos Ceru, v. 21, n. 2, p. 227-240, dez. 2010. Disponível em: <https://www.revistas.usp.br/ceru/article/view/11926/13703>. Acesso em 25 jul. 2015.

LOBO, Luíza. Juana Manso: uma exilada em três pátrias. Revista Gênero, Niterói, v. 9, n. 2 , p. 47-74, 1 . sem. 2009. Disponível em: <http://www.revistagenero.uff.br/index.php/revistagenero/article/viewFile/81/57>. Acesso em: 08 jun. 2018.

MOTTA, Luiz Gonzaga. Análise crítica da narrativa. Brasília: Editora Universidade de Brasília, 2013.

REIS, Marco Aurelio. Crise leva o jornalismo impresso do Rio a reinventar seu negócio. Revista Brasileira de Ensino de Jornalismo, Brasília, v. 5, n. 17, p. 219-234, jul./dez. 2015. Disponível

em: <http://www.fnpj.org.br/rebej/ojs/index.php/rebej/article/viewFile/422/262>. Acesso em: $1^{\text {o }}$ jan. 2016.

SODRÉ, Muniz. Antropológica do espelho: uma teoria da comunicação linear e em rede. Petrópolis, RJ: Vozes, 2002.

SODRÉ, Nelson Werneck. História da imprensa no Brasil. Rio de Janeiro: Graal, 1977.

\section{Textos citados no artigo}

O JORNAL DAS SENHORAS. As nossas assignantes, Rio de Janeiro, n. 1, p. 1, 8, $1^{\circ}$ jan. 1852 .

O JORNAL DAS SENHORAS, Rio de Janeiro, n. 6, p. 44, 8 fev. 1852.

O JORNAL DAS SENHORAS. Resposta, Rio de Janeiro, n. 6, p. 41, 43, 08 fev. 1852.

O JORNAL DAS SENHORAS, Rio de Janeiro, n. 13, p. 103, 27 mar. 1852.

O JORNAL DAS SENHORAS. Uma assignante, Rio de Janeiro, n. 13, p. 103, 27 mar. 1852.

O JORNAL DAS SENHORAS. A's nossas assignantes, Rio de Janeiro, n. 27, p. 27, 4 jul.1852.

O JORNAL DAS SENHORAS. A's nossas assignantes, Rio de Janeiro, n. 28, p. 28, 11 jul. 1852.

O JORNAL DAS SENHORAS, Rio de Janeiro, n. 29, p. 24, 18 de julho de 1852.

O JORNAL DAS SENHORAS. Afastamento em que se tem as mulheres de tudo quanto 
as pode esclarecer e elevar sua alma, Rio de Janeiro, n. 33, p. 51, 15 ago. 1852.

O JORNAL DAS SENHORAS. Artigo II, Rio de Janeiro, n. 35, p. 67, 68, 29 ago. 1852.

O JORNAL DAS SENHORAS, Rio de Janeiro, n. 42, p. 124, 17 out. 1852.

O JORNAL DAS SENHORAS. Emancipação moral da mulher, Rio de Janeiro, n. 43, p. 131, 24 out. 1852.

O JORNAL DAS SENHORAS, Rio de Janeiro, n. 29, p. 232, 17 jul. 1853.

O JORNAL DAS SENHORAS. A's nossas assignantes, Rio de Janeiro, n. 52, p. 52, 30 dez. 1855 .

Submetido em: 28.08.2016

Aprovado em: 09.03.2018 